\title{
Obesity-related hormones and
} endometrial cancer among

\section{postmenopausal women: a nested case-control study within the B FIT cohort}

\author{
Cher M Dallal ${ }^{1,2}$, Louise A Brinton ${ }^{1}$, Douglas C Bauer ${ }^{3}$, Diana S M Buist ${ }^{4}$, Jane A Cauley ${ }^{5}$, \\ Trisha F Hue ${ }^{6}$, Andrea LaCroix ${ }^{7}$, Jeffrey A Tice ${ }^{3}$, Victoria M Chia ${ }^{1,{ }^{+}}$, Roni Falk ${ }^{1}$, \\ Ruth Pfeiffer ${ }^{8}$, Michael Pollak ${ }^{9}$, Timothy D Veenstra ${ }^{10}$, Xia $\mathrm{Xu}^{10}$, James V Lacey Jr${ }^{11}$ \\ for the B FIT Research Group ${ }^{\ddagger}$
}

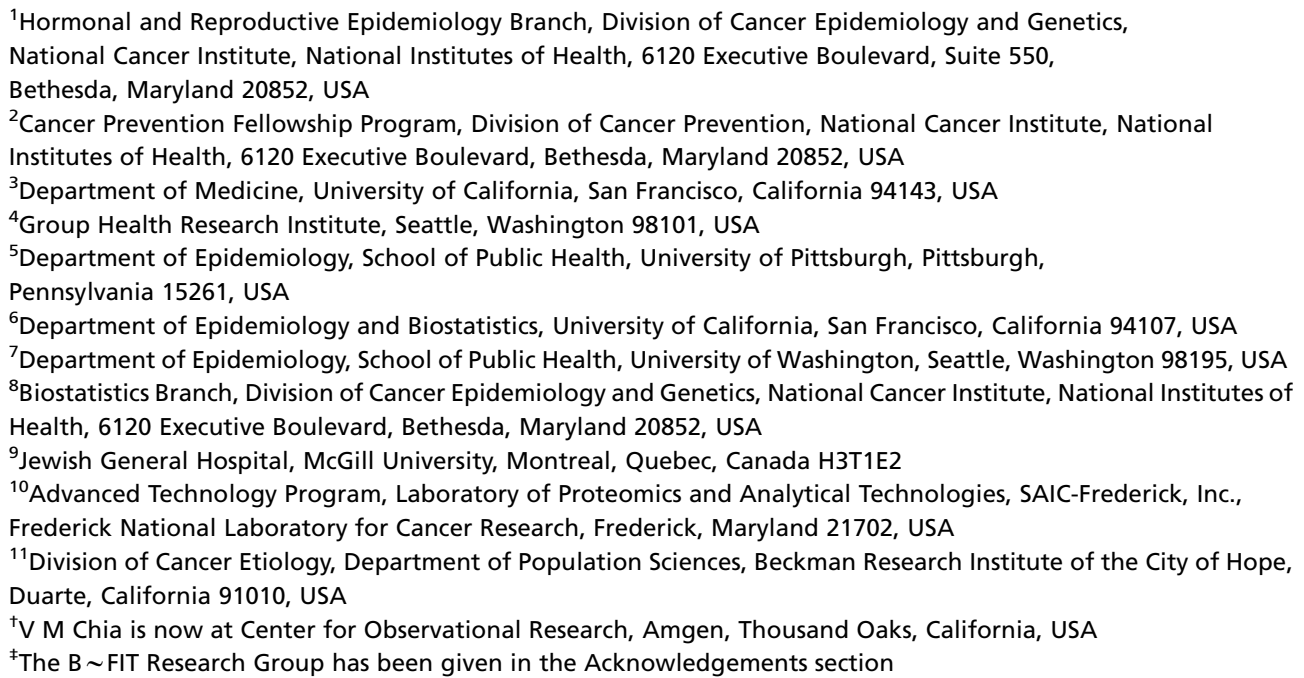

Correspondence should be addressed to C M Dallal Email cher.dallal@nih.gov

\begin{abstract}
Endometrial cancer risk is strongly influenced by obesity, but the mechanisms of action remain unclear. Leptin and adiponectin, secreted from adipose tissue, reportedly play a role in such carcinogenic processes as cell proliferation, angiogenesis, and insulin regulation. In this case-control study, nested within the Breast and Bone Follow-up of the Fracture Intervention Trial ( $n=15$ 595), we assessed pre-diagnostic serum leptin, total adiponectin, and high-molecular-weight (HMW) adiponectin in relation to endometrial cancer among postmenopausal women. During the 10-year follow-up, 62 incident endometrial cases were identified and matched to 124 controls on age, geographical site, time of fasting blood draw at baseline (1992-1993), and trial participation status. Adipokines and C-peptide were measured by ELISA. Odds ratios (ORs) and 95\% confidence intervals (95\% Cls) were estimated via conditional logistic regression, with exposures categorized in tertiles (T). Multivariable models considered C-peptide, BMI $\left(\mathrm{kg} / \mathrm{m}^{2}\right)$, and estradiol (E2) as potential confounders. Endometrial cancer risk was significantly associated with higher leptin levels,
\end{abstract}

http://erc.endocrinology-journals.org DOI: 10.1530/ERC-12-0229
(C) 2013 Society for Endocrinology Printed in Great Britain
Published by Bioscientifica Ltd. 
adjusted for $\mathrm{E} 2$ and $\mathrm{C}$-peptide $\left(\mathrm{OR}_{\mathrm{T} 3}\right.$ vs $\mathrm{T} 1=2.96 ; 95 \% \mathrm{Cl}, 1.21-7.25 ; P$ trend $\left.<0.01\right)$. After further adjustment for BMI, the estimates were attenuated and the positive trend was no longer statistically significant $\left(\mathrm{OR}_{\mathrm{T} 3}\right.$ vs $\mathrm{T} 1=2.11 ; 95 \% \mathrm{Cl}, 0.69-6.44 ; P$ trend $\left.=0.18\right)$. No significant associations were observed with adiponectin or HMW adiponectin and endometrial cancer. Our findings with leptin suggest that the leptin-BMI axis might increase endometrial cancer risk through mechanisms other than estrogen-driven proliferation. Continued exploration of these pathways in larger prospective studies may help elucidate mechanisms underlying observed obesity-endometrial cancer associations.

\section{Introduction}

Obesity is a well-established risk factor for endometrial cancer. Among postmenopausal women, this association may in part be explained by the increase in circulating estrogens that arise from the aromatization of androgens in adipose tissue (Calle \& Kaaks 2004) or through mechanisms involving insulin (Lukanova et al. 2004b) or adipose-derived hormones (van Kruijsdijk et al. 2009). Adipose tissue, an active endocrine organ, also produces and secretes several bioactive peptides, including such adipokines as leptin and adiponectin (van Kruijsdijk et al. 2009).

Leptin, a product of the $o b$ gene, is involved in the regulation of body weight, energy balance, and reproductive function (Paracchini et al. 2005). Results from in vitro studies suggest that leptin exhibits both mitogenic and anti-apoptotic effects, depending on the cell line (Somasundar et al. 2003). Leptin concentrations are elevated among obese individuals (Friedman \& Halaas 1998) and are positively associated with endometrial cancer based on findings from case-control studies (Petridou et al. 2002, Cymbaluk et al. 2008, Ashizawa et al. 2010). To date, no prospective studies have evaluated leptin in relation to endometrial cancer.

Contrary to leptin, adiponectin has been shown to decrease blood glucose and insulin concentrations (Lihn et al. 2005); has anti-inflammatory, antiangiogenic, and proapoptotic properties (Fantuzzi 2005, Roberts et al. 2010); and has been inversely correlated with obesity (Arita et al. 1999). Epidemiological studies that have assessed adiponectin in relation to endometrial cancer risk have generally found higher levels associated with reduced risks (Petridou et al. 2003, Dal Maso et al. 2004, Soliman et al. 2006, Cust et al. 2007, Ashizawa et al. 2010). However, several of these results derive from case-control studies (Petridou et al. 2003, Dal Maso et al. 2004, Soliman et al. 2006, Ashizawa et al. 2010), which used post-diagnostic blood samples and were unable to establish temporality. Only two of these case-control studies included measures of both leptin and adiponectin (post-diagnostic; Petridou et al. 2003, Ashizawa et al. 2010), of which only one assessed the ratio of these two adipokines (Ashizawa et al. 2010). The ratio of adiponectin to leptin may be a more sensitive parameter of insulin resistance than the individual adipokines (Inoue et al. 2005, Cleary et al. 2009); however, this ratio measure has yet to be evaluated in prospective studies of endometrial cancer. To date, only two previous prospective studies have evaluated pre-diagnostic adiponectin in relation to endometrial cancer risk, with one observing an inverse relation (Cust et al. 2007) and the other reporting no association (Soliman et al. 2011). Recent evidence also suggests that high-molecular-weight (HMW) adiponectin may be more biologically active than total adiponectin (Pajvani et al. 2004); however, previous studies have solely measured total adiponectin.

Within the Breast and Bone Follow-up of the Fracture Intervention Trial $(\mathrm{B} \sim \mathrm{FIT})$, we assessed pre-diagnostic leptin, total adiponectin and HMW adiponectin, and their ratios, in relation to incident endometrial cancer risk while also accounting for circulating estrogen and C-peptide levels.

\section{Materials and methods}

We conducted a nested case-control study within B $\sim$ FIT, a longitudinal cohort of participants screened for the Fracture Intervention Trial (FIT). FIT, which has previously been described (Black et al. 1993), was a randomized, placebo-controlled trial designed to test whether alendronate, a bisphosphonate, would reduce the rate of fractures in women with low bone mineral density (Black et al. 1993). In 1992-1993, 22695

Published by Bioscientifica Ltd 
postmenopausal women (ages 55-80 years) were screened for participation at 11 clinical centers in the USA. Potential participants underwent a bone mineral density scan, donated a baseline serum sample, provided clinical examination data (including measured anthropometric and blood pressure), and completed an extensive health history questionnaire that ascertained information on demographic, lifestyle, hormonal, and reproductive factors. Serum samples were originally stored at $-20^{\circ} \mathrm{C}$ for 3 years and then transferred to $-70{ }^{\circ} \mathrm{C}$ for long-term storage. Primary results from FIT were reported in 1996 (Black et al. 1996) and 1998 (Cummings et al. 1998), and a subset of participants who had used alendronate for at least 3 years were invited to participate in FLEX, the FIT Long Term Extension Trial (Black et al. 2006).

$\mathrm{B} \sim$ FIT is a longitudinal cohort composed of FIT screenees $(n=15595)$ from 10 of the original 11 FIT clinical centers; one clinic declined to participate in the follow-up study. Vital status and cause of death of screenees from the ten participating clinics was determined using the National Death Index (NDI). From 2001 to 2004, surviving screenees were contacted by mail and/or telephone and invited to complete a follow-up questionnaire (64\% of eligible women completed the $\mathrm{B} \sim$ FIT questionnaire) that provided additional information on cancers, other health outcomes and reproductive surgeries that occurred since they were screened for FIT, family history of cancer, detailed hormone use, and preventive screening procedures. Women who reported an incident cancer or fracture were asked to give permission for medical record review of those events. In addition, women from the three clinical sites located in Surveillance Epidemiology and End Results (SEER) registry areas (Northern California, Washington, and Iowa) were linked to the cancer registry to identify and confirm cancer diagnoses. All women provided written informed consent. B $\sim$ FIT was approved by the Institutional Review Board (IRB) of each participating site and the University of California, San Francisco Coordinating Center, as well as the National Cancer Institute.

\section{Endometrial cancer ascertainment}

Data on incident endometrial cancer were ascertained from the cancer registry linkages, medical reports, linkage with the NDI for underlying cause of death, and self-report on the B $\sim$ FIT follow-up questionnaire. Of the 81 cases of endometrial cancer identified among B $\sim$ FIT participants since their screening visits, $93.8 \%$ were confirmed by medical record or linkage.
This analysis excluded cases based on the following criteria: baseline serum samples were unavailable or unusable $(n=14)$; personal history of any cancer (other than non-melanoma skin cancer) before FIT baseline $(n=2)$, non-Caucasian race $(n=1)$, and missing BMI information $(n=2)$. The final analysis included 62 endometrial cancer cases. No cases or controls reported using postmenopausal estrogens (oral, injection, or patch) within 4 months of their FIT interview/blood draw.

\section{Selection of controls}

Controls were chosen from among a subcohort of 515 $\mathrm{B} \sim$ FIT participants who were selected for analyses that used the archived serum specimens. This subcohort was randomly selected within 10-year age and clinical strata. The subcohort was further restricted to women with an intact uterus at FIT baseline and exclusions were applied based on the criteria described earlier (i.e. personal history of cancer before baseline, estrogen use within 4 months of baseline, unavailable/unusable samples, non-Caucasian race, or missing BMI data). For each case, we randomly selected two matched controls from among eligible noncases who were alive and had not been diagnosed with endometrial, breast, ovarian, or colorectal cancer before the date of diagnosis of the case. Matching occurred in order of the following: i) geographical site (ten FIT clinics), ii) age at baseline/blood draw \pm 5 years, iii) time of blood draw $\pm 2 \mathrm{~h}$, and iv) trial participation status (screeneeonly, FIT participant, and FLEX participant; this matching criteria was relaxed as necessary to select appropriate controls). Two matched controls were identified for 55 cases and one matched control for six cases. No eligible controls were available for one case; eight controls were selected for four cases that were later found to be ineligible. As adipokine measurements were available for these nine eligible women, we included them in the analysis. The final study population included 62 endometrial cancer cases and 124 controls.

\section{Laboratory assays}

Leptin, adiponectin (total and HMW), and C-peptide assays were conducted in the laboratory of Dr Michael Pollak (Jewish General Hospital, Montreal, Quebec, Canada). Fasting serum concentrations of leptin, adiponectin (total and HMW), and C-peptide were measured in duplicate using standard commercially available ELISA; reagents of these assays were supplied from Millipore Corporation (Billerica, MA, USA).

Published by Bioscientifica Ltd. 
All samples were analyzed using single kit lots. Cases and their matched controls were run on the same plates. Laboratory personnel were blinded to case status of samples. In addition to the laboratory's quality control (QC) samples, three blinded QC samples were included within each batch. Coefficients of variation (within- and between-batch) from masked QC samples ranged from 3.0 to 11.3 for all analytes. The ranges of detection were as follows: leptin, $0.5-100 \mathrm{ng} / \mathrm{ml}$; adiponectin, 787.80-50 $500 \mathrm{ng} / \mathrm{ml}$; HMW adiponectin, 312-50 500 $\mathrm{ng} / \mathrm{ml}$; and C-peptide, $0.2-20 \mathrm{ng} / \mathrm{ml}$. For one subject, the C-peptide value was set to the lowest detection limit $(0.2 \mathrm{ng} / \mathrm{ml})$. Circulating total estradiol (E2), estrone, and estriol were measured using liquid chromatography-mass spectrometry; the published lower limit of quantitation for these serum estrogens is $8 \mathrm{pg} / \mathrm{ml}$ (Xu et al. 2007). Coefficients of variation (within- and between-batch) for serum estrogens were $<1 \%$.

\section{Statistical analysis}

Differences in baseline characteristics and circulating analyte levels by case status were assessed using $t$-tests, Wilcoxon Mann-Whitney, Kruskal-Wallis, or $\chi^{2}$ tests as appropriate. Spearman partial correlations, adjusting for age at blood draw, were estimated for the associations between analytes, BMI, waist circumference, and circulating E2, estrone, and estriol. Conditional logistic regression was used to estimate odds ratios (ORs) and 95\% confidence intervals (95\% CIs) for the relationship between each analyte and endometrial cancer. Tertile categories for each analyte were determined based on the distribution among the controls. In addition to levels of leptin, adiponectin, and HMW adiponectin, we also assessed the ratio of adiponectin to leptin and HMW adiponectin to leptin. Multivariable models were fitted to assess whether each adipokine was associated with endometrial cancer risk, after adjusting for E2, C-peptide, and BMI. The multivariable models included adjustment for i) E2 only, ii) BMI only, iii) BMI and E2, iv) E2 and C-peptide, and v) BMI, E2, and C-peptide. Models were adjusted for E2 rather than estrone or estriol due to the strong main effect of E2 on endometrial cancer in this study population. C-peptide was included as an adjustment factor to account for insulin secretion. Similar models were performed using waist-to-hip ratio (WHR) as the adjustment measure in lieu of BMI. WHR was categorized based on the tertile distribution among controls and missing values were retained in the model as a separate category. Additional adjustment for other baseline covariates (diabetes, hypertension, smoking, gravidity, number of live births, and postmenopausal hormone use) did not substantially alter the results and were not included in the final models. Tests for linear trend were assessed by modeling each exposure as an ordinal variable (coded as 0,1 , and 2). All statistical analyses were performed using the SAS Software Package, version 9.2 (SAS Institute, Cary, NC, USA). All $P$ values were two sided.

\section{Results}

On average, cases and controls were 67 years of age at blood draw (Table 1). Among cases, the mean age at endometrial cancer diagnosis was $73.8 \pm 5.7$ years while the interval between blood draw and diagnosis was $6.4 \pm 3.2$ years. Cases were more likely to be obese (40 vs $22 \%, P=0.01)$, to have reported a history of diabetes and hypertension at baseline, to have never smoked, and to have never been pregnant compared with controls (Table 1). Distributions of each adipokine and C-peptide were similar for cases and controls with the exception of leptin (Table 2); median leptin levels $(\mathrm{ng} / \mathrm{ml}$ ) were significantly higher for cases than controls (median (10th, 90th), $42.4(12.5,92.7)$ and $25.1(8.3,65.7)$ respectively; $P=0.005)$.

Spearman partial correlation coefficients, adjusted for age, showed that serum leptin levels were positively correlated with BMI $(r=0.73, P<0.0001)$ whereas total adiponectin and HMW adiponectin were negatively correlated with BMI $(r=-0.24$ and -0.25 respectively; $P<0.01)$. Circulating total adiponectin was highly correlated with HMW adiponectin $(r=0.95, P<0.0001)$ and both analytes shared similar correlations with the remaining analytes and anthropometric measures (Table 3).

Crude and adjusted ORs from conditional logistic regression models for each adipokine and BMI in relation to endometrial cancer are described in Table 4. Higher BMI was associated with increased endometrial cancer risk ( $P$ trend $=0.02$ ); women with a BMI of $30 \mathrm{~kg} / \mathrm{m}^{2}$ or greater were two times as likely to develop endometrial cancer compared with women with a BMI $<25 \mathrm{~kg} / \mathrm{m}^{2}$ $\left(\mathrm{OR}_{\mathrm{T} 3}\right.$ vs $\left.\mathrm{T} 1=2.44 ; 95 \% \mathrm{CI}, 1.14-5.21\right)$, even after adjustment for $\mathrm{E} 2$ and $\mathrm{C}$-peptide $(P$ trend $=0.05)$. In crude models, higher serum leptin levels were associated with a significant increase in endometrial cancer risk $\left(\mathrm{OR}_{\mathrm{T} 3}\right.$ vs T1 $=3.29 ; 95 \% \mathrm{CI}, 1.41-7.69 ; P$ trend $\left.=0.004\right)$; this positive dose-response persisted even after adjustment for $\mathrm{E} 2$ and C-peptide $\left(\mathrm{OR}_{\mathrm{T} 3}\right.$ vs $\mathrm{T} 1=2.96 ; 95 \% \mathrm{CI}, 1.21-7.25$; $P$ trend $=0.01$ ). However, in models adjusted only for BMI, this association was attenuated and the linear trend

Published by Bioscientifica Ltd 
Table 1 Baseline characteristics of incident endometrial cases and controls.

\begin{tabular}{|c|c|c|c|}
\hline Characteristics & $\begin{array}{l}\text { Incident endometrial } \\
\text { cases }(n=62 ; n(\%))\end{array}$ & $\begin{array}{l}\text { Matched controls } \\
(n=124 ; n(\%))\end{array}$ & $P$ value $^{a}$ \\
\hline \multicolumn{4}{|l|}{ Mean \pm s.D. (range: $10,90 \%)$} \\
\hline Age at blood draw (years) ${ }^{b}$ & $67.4 \pm 5.5(59,74)$ & $67.5 \pm 5.1(60,74)$ & 0.94 \\
\hline Age at diagnosis (years) & $73.8 \pm 5.7(66,80)$ & & \\
\hline Years since menopause & $17.3 \pm 6.2(11.3,23.4)$ & $18.6 \pm 8.0(9.2,29.0)$ & 0.20 \\
\hline Years between blood draw and diagnosis & $6.4 \pm 3.2(1.8,10.3)$ & & \\
\hline BMI $\left(\mathrm{kg} / \mathrm{m}^{2}\right)$ & $29.5 \pm 6.9$ & $26.8 \pm 4.7$ & 0.006 \\
\hline Waist $(\mathrm{cm})^{\mathrm{c}}$ & $100 . \overline{5} \pm 18.5$ & $96.1 \pm 14.1$ & 0.13 \\
\hline Waist-to-hip ratio ${ }^{c}$ & $0.92 \pm 0.1$ & $0.92 \pm 0.09$ & 0.93 \\
\hline \multicolumn{4}{|l|}{$n(\%)$} \\
\hline \multicolumn{4}{|l|}{ BMI $\left(\mathrm{kg} / \mathrm{m}^{2}\right)$} \\
\hline$<25$ & $19(30.7)$ & $50(40.3)$ & \\
\hline $25-29.9$ & $18(29.0)$ & 47 (37.9) & \\
\hline $30-34.9$ & $11(17.7)$ & $19(15.3)$ & \\
\hline $35+$ & $14(22.6)$ & $8(6.5)$ & 0.01 \\
\hline \multicolumn{4}{|l|}{ Trial participation status ${ }^{b}$} \\
\hline Screenee-only & $55(88.7)$ & $89(71.8)$ & \\
\hline FIT & $6(9.7)$ & $23(18.5)$ & \\
\hline FIT/FLEX & $1(1.6)$ & $12(9.7)$ & 0.02 \\
\hline History of diabetes & $8(12.9)$ & $3(2.4)$ & $0.006^{\mathrm{d}}$ \\
\hline History of hypertension & $32(51.6)$ & $36(29.0)$ & 0.003 \\
\hline Measured hypertension & $8(12.9)$ & $13(10.5)$ & 0.65 \\
\hline \multicolumn{4}{|l|}{ Smoking status } \\
\hline Never & $38(61.3)$ & $63(50.8)$ & \\
\hline Former & $23(37.1)$ & $48(38.7)$ & \\
\hline Current & - & $12(9.7)$ & 0.03 \\
\hline \multicolumn{4}{|l|}{ Ever pregnant } \\
\hline Yes & $51(82.3)$ & $116(93.5)$ & \\
\hline No & $11(17.7)$ & $8(6.5)$ & 0.02 \\
\hline \multicolumn{4}{|l|}{ Ever used postmenopausal estrogen pills } \\
\hline Yes & $23(37.1)$ & $32(25.8)$ & \\
\hline No & $39(62.9)$ & $92(74.2)$ & 0.11 \\
\hline \multicolumn{4}{|l|}{ Ever used postmenopausal progestin pills } \\
\hline Yes & $12(19.4)$ & $11(8.9)$ & \\
\hline No & $50(80.6)$ & $111(89.5)$ & 0.05 \\
\hline
\end{tabular}

FIT, participant in the Fracture Intervention Trial; FIT/FLEX, participant in FIT and the Long Term Extension of the FIT Trial. Missing values included in the denominator for calculation of above percentages.

${ }^{a} P$ values calculated using $t$-tests for continuous variables and $\chi^{2}$ for categorical.

${ }^{\mathrm{b}}$ Age at blood draw and trial participation status were matching factors.

'Waist circumference missing for 24 subjects ( 6 cases and 18 controls).

dExact test.

was no longer statistically significant $\left(\mathrm{OR}_{\mathrm{T} 3}\right.$ vs $\mathrm{T} 1=2.11$; 95\% CI, 0.69-6.44; $P$ trend=0.18). Models adjusted for i) BMI and E2 or ii) BMI, E2, and C-peptide resulted in similar findings as those observed in the models adjusted only for BMI (data not shown). Similar results were observed when models were adjusted for WHR in lieu of BMI; WHR was not significantly associated with endometrial cancer risk in this study (data not shown). Leptin remained positively associated with increased risk after adjustment for WHR $\left(\mathrm{OR}_{\mathrm{T} 3}\right.$ vs T1 $=3.70$; $95 \% \mathrm{CI}, 1.4-9.2$; $P$ trend $=0.004$ ) and in models adjusted for WHR, E2, and C-peptide $\left(\mathrm{OR}_{\mathrm{T} 3}\right.$ vs T1 $=2.71 ; 95 \% \mathrm{CI}, 1.00-7.33$; $P$ trend $=0.009$ ). No statistically significant associations were observed between total adiponectin or HMW adiponectin and endometrial cancer risk (Table 4). However, in analyses examining the ratio of total adiponectin to leptin or HMW adiponectin to leptin, significant inverse trends were observed $(P$ trend $=0.02$ and 0.005 respectively). A higher adiponectin-to-leptin ratio was associated with decreased endometrial cancer risk in crude and E2-adjusted models (E2-adjusted $\mathrm{OR}_{\mathrm{T} 3}$ vs $\mathrm{T} 1=0.43 ; 95 \%$ CI, $0.18-1.01 ; P$ trend $=0.03$ ) while an elevated HMW adiponectin-to-leptin ratio was inversely related to endometrial cancer risk even after adjustment for both $\mathrm{E} 2$ and C-peptide $\left(\mathrm{OR}_{\mathrm{T} 3}\right.$ vs T1 $=0.38$; 95\% CI, 0.15-0.94; $P$ trend $=0.02$ ). However, the linear

Published by Bioscientifica Ltd. 
Table 2 Distribution of serum adipokines and C-peptide by case-control status.

\begin{tabular}{|c|c|c|c|}
\hline Analytes & $\begin{array}{c}\text { Incident } \\
\text { endometrial } \\
\text { cases }(n=62)\end{array}$ & $\begin{array}{l}\text { Matched } \\
\text { controls } \\
(n=124)\end{array}$ & P value $^{a}$ \\
\hline \multicolumn{4}{|l|}{ Median (10th, 90th) } \\
\hline Leptin (ng/ml) & $42.4(12.5,92.7)$ & $25.1(8.3,65.7)$ & 0.005 \\
\hline $\begin{array}{l}\text { Total adiponectin } \\
\qquad(\mu \mathrm{g} / \mathrm{ml})\end{array}$ & $14.3(6.7,26.0)$ & $14.6(11.0,30.6)$ & 0.47 \\
\hline $\begin{array}{l}\text { HMW adiponectin } \\
\qquad(\mu \mathrm{g} / \mathrm{ml})\end{array}$ & $8.3(3.5,17.3)$ & $8.8(3.7,20.1)$ & 0.37 \\
\hline C-peptide (ng/ml) & $2.3(1.1,5.2)$ & $2.0(0.96,4.1)$ & 0.14 \\
\hline
\end{tabular}

${ }^{a}$ Wilcoxon's rank sum test for differences in medians.

trends were no longer statistically significant in models adjusted for BMI. Findings from models adjusted for WHR instead of BMI are similar to the results of crude models presented in Table 4 (data not shown).

\section{Discussion}

In this nested case-control study, we evaluated leptin, total adiponectin, and HMW adiponectin in relation to postmenopausal endometrial cancer risk while adjusting for markers of other possible biological pathways underlying the obesity-endometrial cancer association. We observed significantly increased endometrial cancer risk with increasing levels of leptin and the ratio of either total adiponectin or HMW adiponectin to leptin. Women in the highest tertile of circulating leptin had approximately three times the risk of women in the lowest tertile. This significant positive trend persisted after adjustment for E2 and C-peptide but was attenuated and no longer statistically significant once BMI was included in the model. Furthermore, women in the highest tertile of either ratio had an $\sim 60 \%$ reduction in endometrial cancer risk after adjustment for E2. While we adjusted models for BMI for comparability of results with previous studies, adipokines and BMI are correlated; further, BMI is on the causal pathway for endometrial cancer and inclusion as a covariate may result in over adjustment. This is particularly relevant for the leptin models given that leptin and BMI were highly correlated.

Despite the correlation between leptin and BMI in our analysis, endometrial cancer was more strongly associated with leptin than BMI, even after adjustment for E2 and C-peptide. Data from previous studies are limited and based on case-control analyses, where samples were collected after diagnosis (Petridou et al. 2002, Cymbaluk et al. 2008, Ashizawa et al. 2010), but generally support a positive association with leptin, such as the threefold increase in endometrial cancer risk for women with leptin levels in the highest tertile reported by Ashizawa et al. (2010). However, these previous case-control studies measured post-diagnostic leptin levels, which raises questions about the extent to which levels may have been affected by the presence of endometrial cancer. Our prospective cohort study measured leptin in prediagnostic samples collected well before diagnosis. Thus, the positive association with leptin in our study adds methodologically rigorous support for a potential role of leptin in endometrial carcinogenesis.

With regards to total adiponectin and HMW adiponectin, no statistically significant associations were observed in this study. Only two previous prospective studies of adiponectin and endometrial cancer have been conducted (Cust et al. 2007, Soliman et al. 2011), with inconsistent results reported, and further, no previous studies of endometrial cancer have measured the HMW

Table 3 Spearman partial ${ }^{a}$ correlations of serum adipokines, C-peptide, estrogens, and anthropometrics among controls $(n=106)^{b}$.

\begin{tabular}{l} 
Analytes $^{c}$ \\
\hline$r$ ( $P$ value $)$ \\
Leptin \\
Total adiponectin \\
HMW adiponectin \\
C-peptide \\
BMI (kg/m $\left.{ }^{2}\right)$ \\
Estrone \\
Estradiol \\
Estriol
\end{tabular}

\begin{tabular}{c} 
Leptin \\
\hline \\
- \\
- \\
- \\
- \\
- \\
$0.55(<0.0001)$ \\
$0.47(<0.0001)$ \\
$0.53(<0.0001)$
\end{tabular}

\begin{tabular}{c} 
Total \\
adiponectin \\
\hline$-0.26(0.008)$ \\
- \\
- \\
- \\
- \\
$-0.40(<0.0001)$ \\
$-0.41(<0.0001)$ \\
$-0.44(<0.0001)$
\end{tabular}

\begin{tabular}{c} 
HMW \\
adiponectin \\
\hline$-0.31(0.002)$ \\
$0.95(<0.0001)$ \\
- \\
- \\
- \\
$-0.43(<0.0001)$ \\
$-0.42(<0.0001)$ \\
$-0.47(<0.0001)$
\end{tabular}

\begin{tabular}{c} 
C-peptide \\
\hline \\
$0.38(<0.0001)$ \\
$-0.44(<0.0001)$ \\
$-0.44(<0.0001)$ \\
- \\
- \\
$0.30(0.002)$ \\
$0.17(0.08)$ \\
$0.27(0.005)$
\end{tabular}

\begin{tabular}{c} 
BMI $\left(\mathrm{kg} / \mathrm{m}^{2}\right)$ \\
\hline $0.73(<0.0001)$ \\
$-0.24(0.005)$ \\
$-0.25(0.009)$ \\
$0.26(0.007)$ \\
$0.48(<0.0001)$ \\
$0.42(<0.0001)$ \\
$0.46(<0.0001)$
\end{tabular}

Waist $(\mathrm{cm})$

aspearman partial correlation coefficients adjusted for age at blood draw.

b Waist circumference missing for 18 controls.

'Leptin and C-peptide ( $\mathrm{ng} / \mathrm{ml})$; total adiponectin and HMW adiponectin ( $\mu \mathrm{g} / \mathrm{ml})$; estrone, estradiol, and estriol (pmol/l).

http://erc.endocrinology-journals.org DOI: $10.1530 /$ ERC-12-0229
(C) 2013 Society for Endocrinology Printed in Great Britain
Published by Bioscientifica Ltd 
Table 4 Odds ratios ${ }^{\mathrm{a}}$ and $95 \%$ confidence limits from conditional logistic regression models estimating the association between BMI, circulating adipokine levels, and endometrial cancer risk among postmenopausal women.

\begin{tabular}{|c|c|c|c|c|c|}
\hline & Cases/controls & OR $(95 \% \mathrm{Cl})$ & $\begin{array}{c}\text { Estradiol adjusted } \\
\text { OR }(95 \% \mathrm{Cl})\end{array}$ & $\begin{array}{l}\text { Estradiol and } \\
\text { C-peptide adjusted } \\
\text { OR }(95 \% \mathrm{Cl})\end{array}$ & $\begin{array}{c}\text { BMI-adjusted } \\
\text { OR }(95 \% \mathrm{Cl})\end{array}$ \\
\hline \multicolumn{6}{|l|}{ BMI $\left(\mathrm{kg} / \mathrm{m}^{2}\right)$} \\
\hline$<25$ & $19 / 50$ & 1.00 & 1.00 & 1.00 & \\
\hline $25-29.9$ & $18 / 47$ & $1.06(0.46,2.48)$ & $1.03(0.44,2.42)$ & $1.05(0.45,2.46)$ & \\
\hline$\geq 30$ & $25 / 27$ & $2.44(1.14,5.21)$ & $2.30(1.05,5.04)$ & $2.19(0.99,4.83)$ & \\
\hline$P$ trend & & 0.02 & 0.03 & 0.05 & \\
\hline \multicolumn{6}{|c|}{ Leptin $(\mathrm{ng} / \mathrm{ml})$} \\
\hline$\leq 18.29$ & $13 / 41$ & 1.00 & 1.00 & 1.00 & 1.00 \\
\hline $18.30-35.0$ & $15 / 41$ & $1.33(0.54,3.25)$ & $1.30(0.53,3.19)$ & $1.29(0.53,3.18)$ & $1.13(0.44,2.88)$ \\
\hline$\geq 35.10$ & $34 / 42$ & $3.29(1.41,7.69)$ & $3.13(1.31,7.48)$ & $2.96(1.21,7.25)$ & $2.11(0.69,6.44)$ \\
\hline $\bar{P}$ trend & & 0.004 & 0.007 & 0.01 & 0.18 \\
\hline \multicolumn{6}{|c|}{ Total adiponectin $(\mu \mathrm{g} / \mathrm{ml})$} \\
\hline$\leq 11.67$ & $19 / 41$ & 1.00 & 1.00 & 1.00 & 1.00 \\
\hline $11.68-18.0$ & $24 / 40$ & $1.37(0.65,2.89)$ & $1.48(0.69,3.18)$ & $1.99(0.85,4.67)$ & $1.55(0.70,3.43)$ \\
\hline$\geq 18.1$ & $19 / 43$ & $0.87(0.39,1.94)$ & $1.00(0.44,2.31)$ & $1.45(0.56,3.72)$ & $1.31(0.55,3.12)$ \\
\hline $\bar{P}$ trend & & 0.78 & 0.96 & 0.47 & 0.51 \\
\hline \multicolumn{6}{|c|}{ HMW adiponectin $(\mu \mathrm{g} / \mathrm{ml})$} \\
\hline$\leq 6.64$ & $23 / 41$ & 1.00 & 1.00 & 1.00 & 1.00 \\
\hline $6.65-11.49$ & $21 / 40$ & $0.95(0.44,2.04)$ & $0.92(0.42,1.98)$ & $1.07(0.47,2.43)$ & $0.94(0.43,2.08)$ \\
\hline$\geq 11.50$ & $18 / 43$ & $0.62(0.27,1.41)$ & $0.66(0.28,1.52)$ & $0.82(0.32,2.08)$ & $0.87(0.37,2.09)$ \\
\hline $\bar{P}$ trend & & 0.26 & 0.33 & 0.67 & 0.76 \\
\hline \multicolumn{6}{|c|}{ Ratio of total adiponectin to leptin $(\mu \mathrm{g} / \mathrm{ng})$} \\
\hline$\leq 0.34$ & $31 / 42$ & 1.00 & 1.00 & 1.00 & 1.00 \\
\hline $0.35-0.83$ & $15 / 40$ & $0.56(0.27,1.18)$ & $0.57(0.27,1.21)$ & $0.61(0.28,1.33)$ & $0.85(0.36,2.02)$ \\
\hline$\geq 0.84$ & $16 / 42$ & $0.40(0.17,0.90)$ & $0.43(0.18,1.01)$ & $0.46(0.18,1.16)$ & $0.76(0.26,2.24)$ \\
\hline$P$ trend & & 0.02 & 0.03 & 0.08 & 0.61 \\
\hline \multicolumn{6}{|c|}{ Ratio of HMW adiponectin to leptin ( $\mu \mathrm{g} / \mathrm{ng})$} \\
\hline$\leq 0.22$ & $34 / 40$ & 1.00 & 1.00 & 1.00 & 1.00 \\
\hline $0.22-0.51$ & $12 / 41$ & $0.42(0.19,0.91)$ & $0.42(0.19,0.93)$ & $0.43(0.19,1.00)$ & $0.54(0.23,1.27)$ \\
\hline$>0.52$ & $16 / 43$ & $0.35(0.16,0.79)$ & $0.37(0.16,0.87)$ & $0.38(0.15,0.94)$ & $0.56(0.20,1.58)$ \\
\hline$P$ trend & & 0.005 & 0.009 & 0.02 & 0.21 \\
\hline
\end{tabular}

${ }^{a}$ Cases matched to controls on age at baseline/blood draw +5 years, clinic site, time of blood draw $+2 \mathrm{~h}$, trial participation status; controls selected from non-cases alive and disease free at the time of diagnosis of the case and with an intact uterus at FIT baseline. Odds ratios and $95 \%$ confidence limits estimated by conditional logistic.

isoform. Within the Nurses' Health Study (NHS), Soliman et al. (2011) observed no association between adiponectin and endometrial cancer $(n=146$ cases), either before or after adjustment for BMI. Within the European Prospective Investigation into Cancer and Nutrition (EPIC; Cust et al. 2007; $n=284$ cases), an $\sim 50 \%$ reduction in endometrial cancer risk was seen among women in the highest quartile of plasma adiponectin compared with those in the lowest, after adjustment for BMI, waist circumference, and various obesity-related circulating hormones including C-peptide, insulin-like growth factor binding proteins 1 and 2, estrone, and testosterone. Findings from retrospective studies (Petridou et al. 2003, Dal Maso et al. 2004, Soliman et al. 2006, Ashizawa et al. 2010) also support inverse associations ( $\sim 50 \%$ reductions) with higher levels of post-diagnostic total adiponectin.
Possible explanations for the lack of an association with total or HMW adiponectin in our prospective study may include the time interval between blood draw and endometrial cancer development, as was also suggested by Soliman et al. (2011). In the present analysis, the time between blood draw and diagnosis was on average 6 years (interval: 1.8, 10.3), which is comparable with the NHS (average $=7.4$; interval $(2-13)$ but not with EPIC (average $=3.0$; interval: $47,71.0$ ); findings from EPIC support significant reductions in risk. Although the use of pre-diagnostic serum and the time interval between blood draw and endometrial cancer development reduces the possibility of reverse causation in our study, a shorter time interval may reflect changes in insulin levels associated with preclinical disease. The longer interval in our study may in part explain our null findings.

Published by Bioscientifica Ltd. 
However, more research on the representativeness of adiponectin levels over time and in relation to insulin markers is needed.

In our prospective study, higher ratios of total adiponectin to leptin and HMW adiponectin to leptin were associated with a lower risk of endometrial cancer. Both ratios resulted in similar reductions in risk, suggesting that either marker of adiponectin, when measured in relation to leptin, captures relevant biological exposures and may provide more information than that of the individual adipokines alone. Only one previous study ( $n=146$ cases) has evaluated the ratio of these adipokines using post-diagnostic serum (Ashizawa et al. 2010) with results suggesting a sixfold increase in endometrial risk with a higher leptin-to-adiponectin ratio. Recent evidence suggests that the ratio of these adipokines may better predict insulin sensitivity (Inoue et al. 2005, Ashizawa et al. 2010) and further that the balance of these markers, rather than their individual levels, may be important for carcinogenesis (Cleary et al. 2009).

Multiple interrelated pathways are likely to explain the association between obesity and increased endometrial cancer risk, including sex steroids, insulin, inflammation, growth factors, and adipokines (Calle \& Kaaks 2004). Circulating E2 is strongly associated with increased endometrial cancer risk among postmenopausal women, as observed in our study as well as others (Kaaks et al. 2002, Lukanova et al. 2004a). Although this strong estrogen link supports aromatization as a possible explanation for the increased risk of endometrial cancer with obesity, studies have shown significant independent effects of obesity on endometrial cancer even after adjustment for sex hormones (Potischman et al. 1996, Calle \& Kaaks 2004). Our observed positive association between leptin and endometrial cancer persisted after adjustment for E2 but was notably attenuated after adjustment for BMI. This suggests that the leptin-BMI axis might also increase endometrial cancer risk through mechanisms other than estrogen-driven proliferation.

Findings from cell studies support a direct role of leptin on carcinogenic processes such as mitogenesis, angiogenesis, and inflammation (Renehan et al. 2008, Roberts et al. 2010). Leptin synthesis in adipocytes is regulated by various hormones implicated in these processes, including insulin, glucocorticoids, tumor necrosis factor $\alpha$, and reproductive hormones (Garofalo \& Surmacz 2006). Although elevated circulating insulin and glucose levels have been associated with increased endometrial cancer risk, these markers do not fully account for the association between obesity, as measured by BMI, and endometrial cancer risk (Troisi et al. 1997). Other obesity-related hormones, such as leptin and adiponectin, are strong candidates in these processes, as adiponectin levels have been shown to predict insulin resistance and have been suggested to reduce endometrial cancer risk by decreasing circulating insulin and glucose levels. The potential mechanisms underlying the obesityendometrial cancer associations are complex, but our findings suggest that these adipokines may operate independent of circulating E2.

Strengths of this study include the use of prediagnostic serum, prospective follow-up of $\sim 10$ years, the inclusion of multiple adipokines and adjustment for circulating C-peptide and E2, important biomarkers of the insulin and sex steroid pathways. Cases and controls were matched on age and time of blood draw, thus minimizing the potential for these factors to have influenced any observed differences in disease status. Despite these strengths, the limited sample size of this analysis may have hindered our ability to detect significant differences between the circulating markers and endometrial case status, particularly adiponectin and HMW adiponectin. Additionally, we did not have detailed information on histology for the endometrial cases, which precluded us from evaluating potential differences between type I and type II tumors. Adipokine levels were measured at baseline and may not be reflective of exposure over the duration of the follow-up period, a common limitation with prospective biomarker studies. However, Kaplan et al. (2007) found that both adiponectin and leptin appear to be relatively stable during a 3 -year period (intraclass correlation coefficient (ICC) $=0.73$ and 0.58 respectively).

In summary, findings from this prospective study support the notion that higher leptin levels may be predictive of endometrial cancer risk among postmenopausal women and further that the ratio of adiponectin (total and HMW) to leptin may also be informative in studies of endometrial cancer. Continued exploration of these adipokines in larger prospective studies may help elucidate mechanisms underlying observed obesityendometrial cancer associations.

\section{Declaration of interest}

Dr V M Chia is currently an employee and shareholder of Amgen, Inc. The authors declare no conflict of interest.

\section{Funding}

The original FIT study was funded by Merck Research Laboratories. B FIT was funded by the National Cancer Institute (contract \#N02-CP-01019).

Published by Bioscientifica Ltd. 


\section{Acknowledgements}

The authors thank Stephanie Litwack-Harrison MPH (UCSF, San Francisco, CA, USA), and Eric Boyd (IMS, Silver Spring, MD, USA) for their invaluable assistance with study and data management. They would also like to thank the $\mathrm{B} \sim \mathrm{FIT}$ investigators and participants for their contributions to this study. B FIT Research Group members: i) Coordinating Center - University of California, San Francisco: D C Bauer MD, T F Hue PhD, MPH, Stephanie Litwack-Harrison MPH, Susan Rubin MPH, J A Tice MD; ii) Clinical Centers Group Health Cooperative of Puget Sound, Seattle: D S M Buist MD and A Z LaCroix PhD; Kaiser Permanente Center for Health Research, Portland: Emily Harris PhD; Stanford Medical Center, Palo Alto: William L Haskell PhD; University of California, San Diego: Elizabeth Barrett-Connor MD; University of lowa, lowa City: James C Torner PhD; University of Maryland, Baltimore: Marc C Hochberg MD; University of Miami Medical School: Silvina Levis MD; University of Pittsburgh: J A Cauley DrPH; University of Tennessee, Memphis: Suzanne Satterfield MD, MPH; Wake Forest University, Winston-Salem: Sara A Quandt PhD. iii) National Cancer Institute: L A Brinton PhD and J V Lacey Jr PhD, MPH.

\section{References}

Arita Y, Kihara S, Ouchi N, Takahashi M, Maeda K, Miyagawa J, Hotta K, Shimomura I, Nakamura T, Miyaoka K et al. 1999 Paradoxical decrease of an adipose-specific protein, adiponectin, in obesity. Biochemical and Biophysical Research Communications 257 79-83. (doi:10.1006/bbrc. 1999.0255)

Ashizawa N, Yahata T, Quan J, Adachi S, Yoshihara K \& Tanaka K 2010 Serum leptin-adiponectin ratio and endometrial cancer risk in postmenopausal female subjects. Gynecologic Oncology 119 65-69. (doi:10.1016/j.ygyno.2010.07.007)

Black DM, Reiss TF, Nevitt MC, Cauley J, Karpf D \& Cummings SR 1993 Design of the Fracture Intervention Trial. Osteoporosis International 3 (Suppl 3) S29-S39. (doi:10.1007/BF01623005)

Black DM, Cummings SR, Karpf DB, Cauley JA, Thompson DE, Nevitt MC, Bauer DC, Genant HK, Haskell WL, Marcus R et al. 1996 Randomised trial of effect of alendronate on risk of fracture in women with existing vertebral fractures. Fracture Intervention Trial Research Group. Lancet 348 1535-1541. (doi:10.1016/S0140-6736(96)07088-2)

Black DM, Schwartz AV, Ensrud KE, Cauley JA, Levis S, Quandt SA, Satterfield S, Wallace RB, Bauer DC, Palermo L et al. 2006 Effects of continuing or stopping alendronate after 5 years of treatment: the Fracture Intervention Trial Long-term Extension (FLEX): a randomized trial. Journal of the American Medical Association 296 2927-2938. (doi:10.1001/jama.296.24.2927)

Calle EE \& Kaaks R 2004 Overweight, obesity and cancer: epidemiological evidence and proposed mechanisms. Nature Reviews. Cancer 4 579-591. (doi:10.1038/nrc1408)

Cleary MP, Ray A, Rogozina OP, Dogan S \& Grossmann ME 2009 Targeting the adiponectin:leptin ratio for postmenopausal breast cancer prevention. Frontiers in Bioscience: a Journal and Virtual Library 1 329-357.

Cummings SR, Black DM, Thompson DE, Applegate WB, Barrett-Connor E, Musliner TA, Palermo L, Prineas R, Rubin SM, Scott JC et al. 1998 Effect of alendronate on risk of fracture in women with low bone density but without vertebral fractures: results from the Fracture Intervention Trial. Journal of the American Medical Association 280 2077-2082. (doi:10.1001/jama.280.24.2077)

Cust AE, Kaaks R, Friedenreich C, Bonnet F, Laville M, Lukanova A, Rinaldi S, Dossus L, Slimani N, Lundin E et al. 2007 Plasma adiponectin levels and endometrial cancer risk in pre- and postmenopausal women. Journal of Clinical Endocrinology and Metabolism 92 255-263. (doi:10.1210/jc.2006-1371)

Cymbaluk A, Chudecka-Glaz A \& Rzepka-Gorska I 2008 Leptin levels in serum depending on body mass index in patients with endometrial

http://erc.endocrinology-journals.org DOI: $10.1530 / E R C-12-0229$
(C) 2013 Society for Endocrinology Printed in Great Britain hyperplasia and cancer. European Journal of Obstetrics, Gynecology, and Reproductive Biology 136 74-77. (doi:10.1016/j.ejogrb.2006.08.012)

Dal Maso L, Augustin LS, Karalis A, Talamini R, Franceschi S, Trichopoulos D, Mantzoros CS \& La Vecchia C 2004 Circulating adiponectin and endometrial cancer risk. Journal of Clinical Endocrinology and Metabolism 89 1160-1163. (doi:10.1210/jc.2003-031716)

Fantuzzi G 2005 Adipose tissue, adipokines, and inflammation. Journal of Allergy and Clinical Immunology 115 911-919 (quiz 920). (doi:10.1016/ j.jaci.2005.02.023)

Friedman JM \& Halaas JL 1998 Leptin and the regulation of body weight in mammals. Nature 395 763-770. (doi:10.1038/27376)

Garofalo C \& Surmacz E 2006 Leptin and cancer. Journal of Cellular Physiology 207 12-22. (doi:10.1002/jcp.20472)

Inoue M, Maehata E, Yano M, Taniyama M \& Suzuki S 2005 Correlation between the adiponectin-leptin ratio and parameters of insulin resistance in patients with type 2 diabetes. Metabolism 54 281-286. (doi:10.1016/j.metabol.2004.09.006)

Kaaks R, Lukanova A \& Kurzer MS 2002 Obesity, endogenous hormones, and endometrial cancer risk: a synthetic review. Cancer Epidemiology, Biomarkers \& Prevention 11 1531-1543.

Kaplan RC, Ho GY, Xue X, Rajpathak S, Cushman M, Rohan TE, Strickler HD, Scherer PE \& Anastos K 2007 Within-individual stability of obesityrelated biomarkers among women. Cancer Epidemiology, Biomarkers \& Prevention 16 1291-1293. (doi:10.1158/1055-9965.EPI-06-1089)

van Kruijsdijk RC, van der Wall E \& Visseren FL 2009 Obesity and cancer: the role of dysfunctional adipose tissue. Cancer Epidemiology, Biomarkers \& Prevention 18 2569-2578. (doi:10.1158/1055-9965.EPI-09-0372)

Lihn AS, Pedersen SB \& Richelsen B 2005 Adiponectin: action, regulation and association to insulin sensitivity. Obesity Reviews 6 13-21. (doi:10.1111/j.1467-789X.2005.00159.x)

Lukanova A, Lundin E, Micheli A, Arslan A, Ferrari P, Rinaldi S, Krogh V, Lenner P, Shore RE, Biessy C et al. 2004a Circulating levels of sex steroid hormones and risk of endometrial cancer in postmenopausal women. International Journal of Cancer 108 425-432. (doi:10.1002/ijc.11529)

Lukanova A, Zeleniuch-Jacquotte A, Lundin E, Micheli A, Arslan AA, Rinaldi S, Muti P, Lenner P, Koenig KL, Biessy C et al. 2004b Prediagnostic levels of C-peptide, IGF-I, IGFBP-1, -2 and -3 and risk of endometrial cancer. International Journal of Cancer 108 262-268. (doi:10.1002/ijc.11544)

Pajvani UB, Hawkins M, Combs TP, Rajala MW, Doebber T, Berger JP, Wagner JA, Wu M, Knopps A, Xiang AH et al. 2004 Complex distribution, not absolute amount of adiponectin, correlates with thiazolidinedione-mediated improvement in insulin sensitivity. Journal of Biological Chemistry 279 12152-12162. (doi:10.1074/jbc. M311113200)

Paracchini V, Pedotti P \& Taioli E 2005 Genetics of leptin and obesity: a HuGE review. American Journal of Epidemiology 162 101-114. (doi:10.1093/aje/kwi174)

Petridou E, Belechri M, Dessypris N, Koukoulomatis P, Diakomanolis E, Spanos E \& Trichopoulos D 2002 Leptin and body mass index in relation to endometrial cancer risk. Annals of Nutrition and Metabolism 46 147-151. (doi:10.1159/000063081)

Petridou E, Mantzoros C, Dessypris N, Koukoulomatis P, Addy C, Voulgaris Z, Chrousos G \& Trichopoulos D 2003 Plasma adiponectin concentrations in relation to endometrial cancer: a case-control study in Greece. Journal of Clinical Endocrinology and Metabolism $\mathbf{8 8}$ 993-997. (doi:10.1210/jc.2002-021209)

Potischman N, Hoover RN, Brinton LA, Siiteri P, Dorgan JF, Swanson CA, Berman ML, Mortel R, Twiggs LB, Barrett RJ et al. 1996 Case-control study of endogenous steroid hormones and endometrial cancer. Journal of the National Cancer Institute 88 1127-1135. (doi:10.1093/jnci/ 88.16.1127)

Renehan AG, Roberts DL \& Dive C 2008 Obesity and cancer: pathophysiological and biological mechanisms. Archives of Physiology and Biochemistry 114 71-83. (doi:10.1080/13813450801954303) 
Roberts DL, Dive C \& Renehan AG 2010 Biological mechanisms linking obesity and cancer risk: new perspectives. Annual Review of Medicine 61 301-316. (doi:10.1146/annurev.med.080708.082713)

Soliman PT, Wu D, Tortolero-Luna G, Schmeler KM, Slomovitz BM, Bray MS, Gershenson DM \& Lu KH 2006 Association between adiponectin, insulin resistance, and endometrial cancer. Cancer 106 2376-2381. (doi:10.1002/cncr.21866)

Soliman PT, Cui X, Zhang Q, Hankinson SE \& Lu KH 2011 Circulating adiponectin levels and risk of endometrial cancer: the prospective Nurses' Health Study. American Journal of Obstetrics and Gynecology 167 e161-e165. (doi:10.1016/j.ajog.2010.08.045)
Somasundar P, Yu AK, Vona-Davis L \& McFadden DW 2003 Differential effects of leptin on cancer in vitro. Journal of Surgical Research 113 50-55. (doi:10.1016/S0022-4804(03)00166-5)

Troisi R, Potischman N, Hoover RN, Siiteri P \& Brinton LA 1997 Insulin and endometrial cancer. American Journal of Epidemiology 146 476-482. (doi:10.1093/oxfordjournals.aje.a009301)

Xu X, Roman JM, Issaq HJ, Keefer LK, Veenstra TD \& Ziegler RG 2007 Quantitative measurement of endogenous estrogens and estrogen metabolites in human serum by liquid chromatography-tandem mass spectrometry. Analytical Chemistry 79 7813-7821. (doi:10.1021/ ac070494j)

Received in final form 16 November 2012

Accepted 5 December 2012

Made available online as an Accepted Preprint

5 December 2012
Published by Bioscientifica Ltd. 